\title{
実用特殊鋼の炭化物の電解分離による研究 $(\mathrm{V})^{*}$
}

(三, 三の令間ダイス鋼の炭化物について)

\author{
佐藤知雄 ${ }^{* *}$. 西沢泰二*** . 村井弘佑 $* * *$ \\ STUDY ON CARBIDES IN COMMERCIAL SPECIAL STEELS \\ BY ELECTROLYTIC ISOLATION (V) \\ (On Carbides in Several Cold-working Die Steels)
}

Tomo-o Sato, Dr. Eng., Taiji Nishizawa and Kousuke Murai

Synopsis:

The nature of the carbides in several cold-working die steels were studied by the electrolytic isolation, subsequent chemical analysis and $\mathrm{X}$-ray examination, and the following results were obtained:

(1) The carbides in annealed high-C high- $\mathrm{C}_{\mathrm{T}}$ die steel are $\mathrm{M}_{7} \mathrm{C}_{3}$, as reported in the previous paper. (Tetsu-țo-Hagané, Vol. 42 (1956) p. 1118) While, the carbides in the steels, modified by the addition of $\mathrm{W}(3 \%)$ or Mo $(1 \%)$, are principally $\mathrm{M}_{23} \mathrm{C}_{6}$. The high-C high-W die steel contains very large amounts of $\mathrm{M}_{23} \mathrm{C}_{6}$, accompanied some $\mathrm{M}_{6} \mathrm{C}$.

(2) The most of $\mathrm{Cr}, \mathrm{W}$ and $\mathrm{Mo}$ in the annealed steels are tied up in the carbides.

After usual quenching treatment of these steels, the considerable carbides are undissolved in austenite, so that at such a quenching temperature, $\mathrm{C}, \mathrm{Cr}, \mathrm{W}$ and $\mathrm{Mo}$ contents of the austenite are less than those of the steel as a whole.

(3) In the course of tempering of these steels, $\varepsilon$ and $\theta$ carbides precipitated in martensite change to another special carbides, depending on the time and temperature of tempering. That is, in the high-C high-Cr-W steel, carbide reactions proceed as $\varepsilon \rightarrow \theta \rightarrow M_{7} C_{3} \rightarrow M_{23} C_{6}$, and in the high-C high-W steel, as $\varepsilon \rightarrow \theta \rightarrow M_{6} C \rightarrow M_{28} C_{6}$.

\section{I. 緒宣}

第I 報1) において高 C-高 Cr ダイス鋼 (SKD 1)の 炭化物の電解分離法による研究結果を報告した。本報は その続報であつて, 高 $\mathrm{C}-$ 高 $\mathrm{Cr}-\mathrm{W}$ ダイス鋼 (SKD2), 高 C-高 Cr-Mo ダイス鋼 (SKD 11)，ならびに高 C高 W ダイス鋼 (SKD 3) の炭化物について同様の実 験を行つた結果を総括したものである.Table 1 に実 駼試料の化学組成を示したが，この中で SKD 1 鋼は第 I 報にて用いたものと全く同一の鋼材を使用し，比較検 討の基準とした:

\section{II. 実験結果ならびに考察}

（1）焼鈍鋼中の炭化物の量，組成および結晶構造 $800^{\circ} \mathrm{C}$ に 5 時間加熱後徐冷した試片より，炭化物を電 解分離し，これ宾化学分析ならびにX線分析した結果は Table 2 に示すごとくである.

いずれの鋼も含有炭素量が的いので，存在する炭化物 の量がきわめて多く,とくに高 C-高W 鋼 (SKD3) に おいては銓全体の 42\% が炭化物である.このように多 量の炭化物が鋼中に存在することが, この種の鋼の耐磨 耗性を強大としておるのであろうが, その反面, 鍜造性

Table 1. Chemical composition of specimens.

\begin{tabular}{c|c|c|c|c|c|c|c|c|c|c|c|}
\hline Steel designation & C & Si & Mn & P & S & Cr & W \\
\hline S K D 1 & $2 \cdot 25$ & $\cdot 44$ & $\cdot 50$ & $\cdot 015$ & $\cdot 020$ & $12 \cdot 03$ & - \\
S K D 2 & $1 \cdot 91$ & $\cdot 31$ & $\cdot 35$ & $\cdot 021$ & $\cdot 024$ & $14 \cdot 27$ & $2 \cdot 77$ \\
S K D 11 & $1 \cdot 41$ & $\cdot 27$ & $\cdot 32$ & $\cdot 017$ & $\cdot 023$ & $13 \cdot 13$ & - \\
S K D 3 & $2 \cdot 06$ & $\cdot 35$ & $\cdot 37$ & $\cdot 025$ & $\cdot 026$ & $2 \cdot 73$ & $10 \cdot 32$ & $1 \cdot 20$ \\
\hline
\end{tabular}

* 昭和 32 年 4 只日本会講演会に発表, ***東北大学工学部教授, 工搏, *** 東北大学工学部金属工学科 
Table 2. Carbides in annealed specimens.

\begin{tabular}{|c|c|c|c|c|c|c|}
\hline \multirow{2}{*}{$\begin{array}{c}\text { Steel } \\
\text { designation }\end{array}$} & \multirow{2}{*}{$\begin{array}{l}\text { Weight } \% \\
\text { of carbides }\end{array}$} & \multicolumn{4}{|c|}{ Chemical composition of carbides (\%) } & \multirow{2}{*}{$\begin{array}{l}\mathrm{X} \text {-ray analysis of } \\
\text { carbides }\end{array}$} \\
\hline & & $\langle C\rangle$ & $\langle\mathrm{Cr}\rangle$ & $\langle W\rangle$ & $\langle\mathrm{Mo}\rangle$ & \\
\hline $\begin{array}{l}\text { S K D 1 } \\
\text { S K D } 2 \\
\text { S K D 11 } \\
\text { S K D } 3\end{array}$ & $\begin{array}{l}25 \cdot 8 \\
30 \cdot 3 \\
23 \cdot 5 \\
42 \cdot 0\end{array}$ & $\begin{array}{l}8 \cdot 7 \\
6 \cdot 3 \\
6 \cdot 0 \\
4 \cdot 9\end{array}$ & $\begin{array}{r}43 \cdot 0 \\
43 \cdot 0 \\
50 \cdot 6 \\
6.0\end{array}$ & $\frac{\overline{7 \cdot 4}}{22 \cdot 3}$ & $\begin{array}{l}- \\
4 \cdot 8 \\
-\end{array}$ & $\begin{array}{l}\mathbf{M}_{7} \mathrm{C}_{8} \\
\mathrm{M}_{28} \mathrm{C}_{6}+\mathrm{M}_{7}^{\prime} \mathrm{C}_{8} \\
\mathrm{M}_{23} \mathrm{C}_{6} \\
\mathrm{M}_{93} \mathrm{C}_{6}+\mathrm{M}_{6}^{\prime} \mathrm{C}\end{array}$ \\
\hline
\end{tabular}

が昰く，靱性が低いとされておることの主原因であると 思和机る。

高 $\mathrm{Cr}$ 鋼中の炭化物は, 少量のWむるいは Mo の添 加によつていちじるしく影響されるので, Fe-Cr-C 系 状態図から推定されるものと洼く異つている・すなる ち高 C-高 $\mathrm{Cr}$ ダイス鋼（SKD 1）の焼鈾組織中には $\mathrm{M}_{7} \mathrm{C}_{3}$ 型炭化物のみ存在するここが, 状態図からる屯た 実験的にも雄認されたのであるが1，SKD 1 鋼に約 3\% のWを添加した SKD2 鋼においては, $\mathrm{M}_{23} \mathrm{C}_{6}$ 型炭化物 が主要な炭化物となつていて，こ狆に若干の $\mathrm{M}_{7} \mathrm{C}_{3}$ が 附随的に現れている.また, 高 $\mathrm{C}-$ 高 $\mathrm{Cr}-\mathrm{Mo}$ 鋼 (SKD 11)においても，Mo が含まれない上すればその組成点 は $\mathrm{Fe}-\mathrm{Cr}-\mathrm{C}$ 系状態図中の $\alpha+\mathrm{M}_{7} \mathrm{C}_{3}$ の界域内にあるに も拘らず，約 $1 \%$ の Mo が添加されたために， $\mathbf{M}_{23} \mathrm{C}_{6}$ 型炭化物の多が存在する. しかし，高 $\mathrm{C}$-高W銅 (SKD 3) の組成点は $\mathrm{Fe}-\mathrm{W}-\mathrm{C}$ 系状態図 ${ }^{2}$ 中の $\alpha+\mathrm{M}_{23} \mathrm{C}_{6}+$ $\mathrm{M}_{6} \mathrm{C}$ の界域内にあり, 本研究の結果と合致している. なお，上記した $\mathrm{M}_{7} \mathrm{C}_{3} ， \mathrm{M}_{23} \mathrm{C}_{6}$ ならびに $\mathrm{M}_{6} \mathrm{C}$ は，それ ぞ秃 $(\mathrm{Cr}, \mathrm{Fe}, \mathrm{W}, \mathrm{Mo})_{7} \mathrm{C}_{3},(\mathrm{Cr}, \mathrm{Fe}, \mathrm{W}, \mathrm{Mo})_{23} \mathrm{C}_{6}$, なら びに (Fe,W, Mo, Cr) ${ }_{8} \mathrm{C}$ の略記号であつて, $\mathrm{M}_{28} \mathrm{C}_{6}$ は タンダステン工具鋼引または不銹鋼中にしばしば現れる 炭化物， $\mathrm{M}_{6} \mathrm{C}$ 滈速度鋼中の主要な炭化物である4。

Table 2 に示した炭化物の量とその組成の分析値を基 礎として計算すれば，烍針組織中の地鉄の組成を推定す るととが出来る. Table 3 はかくしてえられた地鉄中 の Cr, W ならびに Mo 滑度であつて, 焼鈍状態にお

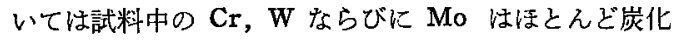
物中に浱縮しており，地鉄中に固溶しておる量はき和め て少いことが知られる。

Table 3. $\mathrm{Cr}, \mathrm{W}$ and $\mathrm{Mo}$ concentrations in ferrite in annealed specimens (calculated)

\begin{tabular}{c|c|c|c}
\hline Steel designation & {$[\mathrm{Cr}]$} & {$[\mathrm{W}]$} & {$[\mathrm{Mo}]$} \\
\hline S K D 1 & 1.3 & - & - \\
S KD 2 & 1.8 & $0 \cdot 7$ & - \\
S K D11 & 1.6 & - & $0 \cdot 1$ \\
S K D 3 & 0.3 & 1.5 & - \\
\hline
\end{tabular}

（2）焼入堸中の炭化物の量之組成

各試料它 $800 \sim 1100^{\circ} \mathrm{C}$ の各温度见 1 時間加熱後々日 温度より油焼入しな場合の焼入硬度，な.らびに焼入組缄 中に未溶解のま〉残存している炭化物の重量\%をFig.1 ならびに Fig. 2 に示した. 高C-高W鋼(SKD 3) は他 の高 C-高 $\mathrm{Cr}$ 系ダイス鋼に比して変態点が低いので, $850^{\circ} \mathrm{C}$ からの焼入によつて最高硬度に達し, さらに焼入 温度が高くなるにつれて残留オーステナイト量が增加す るために暁入硬度がいちでるしく低下する。つぎに。

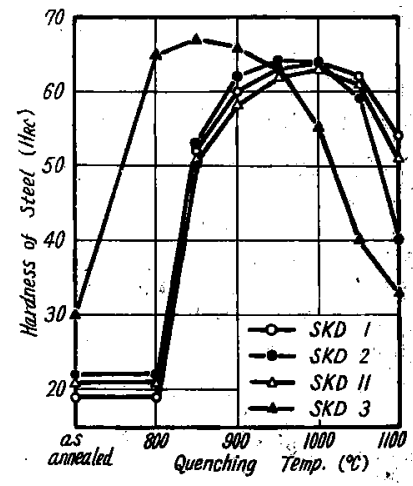

Fig. 1. Hardening of cold-work die steels due to quenching.

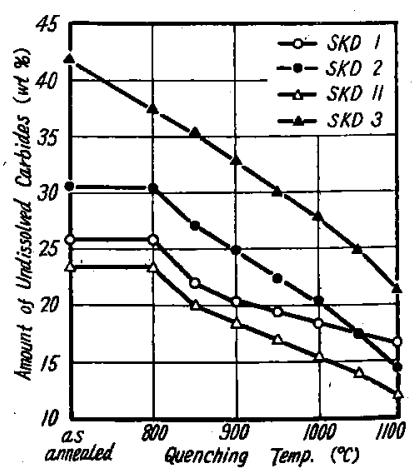

Fig: 2. Dissolution of carbides into austenite due to austenitizing. 
SKD 1，SKD 2・ならびた SKD 11 の烧入温度一硬度 曲線を此較して見ると，SKD 2 はSKD 1 よりも最高の 硬度を示す焼入㴜度が僅がに低温側にずれておりら，ま 大 SKD 11 は SKD 1 よりる含有炭桨量がかなり低い にも拘らず，ほメ゙同一の煍入温度にて最高硬度を示して いる.

これらの事象は， $\mathrm{M}_{28} \mathrm{C}_{5}$ 型炭化物が $\mathrm{M}_{7} \mathrm{C}_{8}$ 型宸化物 よりをオーステナイトに溶け込み易いという事実致か。 ら説明される.すなお方，Fig. 2 の焼入温度一炭化物 量曲線から知られるように， $\mathrm{M}_{7} \mathrm{C}_{8}$ のみを含有している SKD 1 に比して， $\mathrm{M}_{28} \mathrm{C}_{6}$ を主要炭北物乞して含有して いるSKD2, SKD 11, ならびに SKD 3 たおいては いずれる，煯入温度の上昇に伴う炭化物量の減少率が大 であり，したがつて，オーステナイトのの炭素ならびに 合金元素の溶解量が大であるから，比較的低温度の㻗入 几ようて最高硬度に達し，燒入温度がさらに上昇すうと とも伙，牫留オーステナイト量が堌加するのである。

烧文組織中の未溶解炭化物の $\mathrm{Cr}, \mathrm{W}, \mathrm{Mo}$ 搌度の你

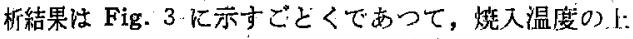

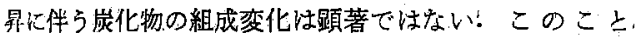

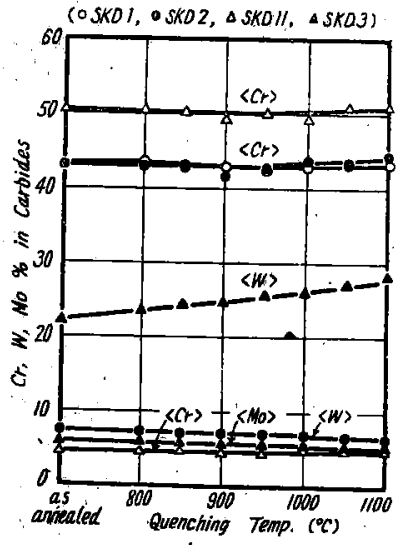

Fig. 3, $\mathrm{Cr}, \mathrm{W}$ and $\mathrm{Mo}$ concentration in carbides in the quenched die steels.
はオー不テル゙イト化加熱にさいして炭化物はその化学組 成をほとんど变ずるととなく，単にオーステナイトに溶 け込むこと意味している。だ゙し，SKD 3 の未溶解 炭化物の W 浱度が暁入温度の上昇に伴つて若干增加壬 る傾向が認められるが，これは， $\mathrm{M}_{23} \mathrm{C}_{6}$ がオーステナイ トに溶け込为易い炭化物であるに对して，W浱度の高い $\mathrm{M}_{6} \mathrm{C}$ 型炭化物は才一ステナイトに溶け込み難く，乙た がつて焼入温度の上昇に伴つて $\mathrm{M}_{6} \mathrm{C} ; \mathrm{M}_{28} \mathrm{C}_{6}$ の存在比 が增大するために，末溶解炭化物全体としての平均のW 濃度が増加したものと考光られる.Fig. 4；5，6 は，烧 入銅中の炭化物の量とその分析結果を基礎として計算し た，焼入鋼中の基質の組成である。字た，これらの鋼を 実用の燒入温度から烧入れた場合の硬度, 未溶解炭化物 量，ならびに基質の組成を以上の結果から総括すれば Table 4 のごとくである.

(3) 焼戻に伴引炭化物の挙動

（a）鋼の焼屌硬度ならびに焼原示差熱膨脤の測定絬 果

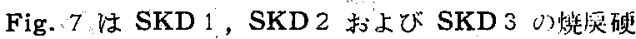

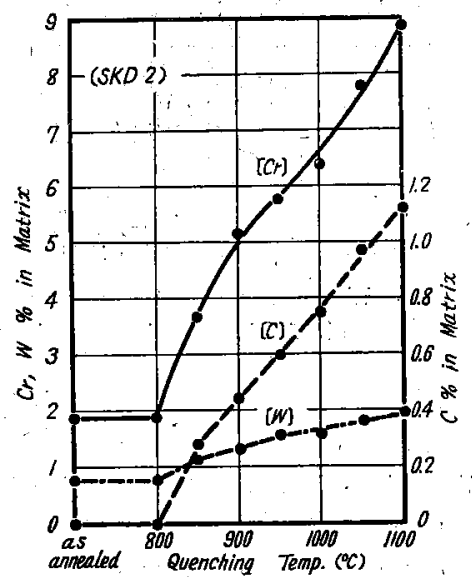

Fig. 4. C. $\mathrm{Cr}$ and $\mathrm{W}$ concentration in matrix in the quenched high- $\mathrm{C}$ high $-\mathrm{Cr}-\mathrm{W}$ die steel.

Table 4. Amounts of undissolved carbides, and chemical composition of matrix in the quenched die steels.

\begin{tabular}{|c|c|c|c|c|c|c|c|}
\hline \multirow{2}{*}{$\begin{array}{c}\text { Steel } \\
\text { designation }\end{array}$} & \multirow{2}{*}{$\begin{array}{l}\text { Quenching } \\
\text { temp }\left({ }^{\circ} \mathrm{C}\right)\end{array}$} & \multirow{2}{*}{$\begin{array}{l}\text { Hardness of } \\
\text { steel (HRc) }\end{array}$} & \multirow{2}{*}{$\begin{array}{l}\text { Undissolved } \\
\text { carbides (wt } \%)\end{array}$} & \multicolumn{4}{|c|}{ Composition of matrix $(\%)$} \\
\hline & & & & {$[\mathbf{C}]$} & [Cr] & [W] & [Mo] \\
\hline $\begin{array}{l}\text { S K D } 1 \\
\text { S K D } 2 \\
\text { SKD } 11 \\
\text { SKD } 3\end{array}$ & $\begin{array}{r}950 \\
980 \\
1000 \\
850\end{array}$ & $\begin{array}{r}63 \\
64 \\
63 \\
66\end{array}$ & $\begin{array}{l}19 \\
21 \\
16 \\
35\end{array}$ & $\begin{array}{l}0.6 \\
0.7 \\
0.5 \\
0.5\end{array}$ & $\begin{array}{l}4 \cdot 4 \\
6 \cdot 4 \\
6 \cdot 0 \\
1 \cdot 0\end{array}$ & $\frac{\overline{1}}{2 \cdot 7}$ & $\frac{-}{0.5}$ \\
\hline
\end{tabular}




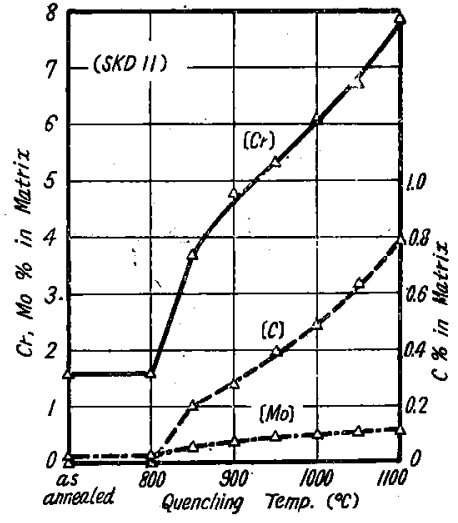

Fig. 5. $\mathrm{C}, \mathrm{Cr}$ and $\mathrm{Mo}$ concentration in matrix in the quenched high-C high-Cr-Mo die steel.

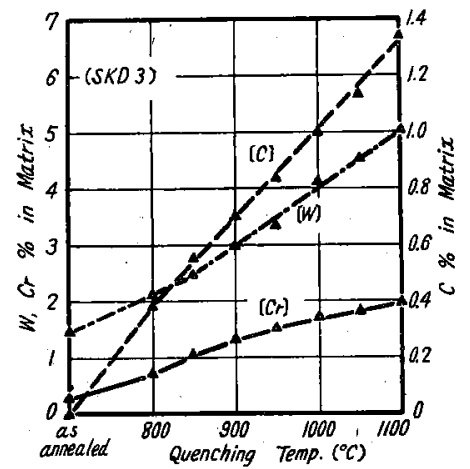

Fig. 6. $\mathrm{C}, \mathrm{W}$ and $\mathrm{Cr}$ concentration in matrix in the quenched high-C high-W die steel.

度一温度曲線（1 時間焼戾）である.いずれの鋼におい ても, 焼入温度が高い程, 高温焼戻における硬度が高く かつ，焼戻硬化が顕著に現れているが，注意すべきこと は SKD 1 ならびに SKD2 の㹸戻硬化温度が 400〜 $500^{\circ} \mathrm{C}$ であるに対して，SKD 3 において注 $300^{\circ} \mathrm{C}$ 附 近である.これは, Fig. 8 に示した焼戻示差熱膨脹曲線 (950 ${ }^{\circ} \mathrm{C}$ より焼入した試料を約 $1^{\circ} \mathrm{C} / \mathrm{mn}$ の割合で加熱) に明かなごとく, SKD 1 ならびに SKD 2 の残留オー ステナイトが高温焼戻によつて分解するに対して，SKD 3 は $\mathrm{Cr}$ 含有量が低いために, その残留オーステナイ 卜は $250 \sim 300^{\circ} \mathrm{C}$ の焼㞔によつて分解することによるの である。

なお Fig. 7 の示差熱膨脹曲線に現れた膨脹あるいは 収緶については，つぎのごとくに考光られる。

A：マルテンサイトが分解して，も炭化物が析出する ことによる収䌅

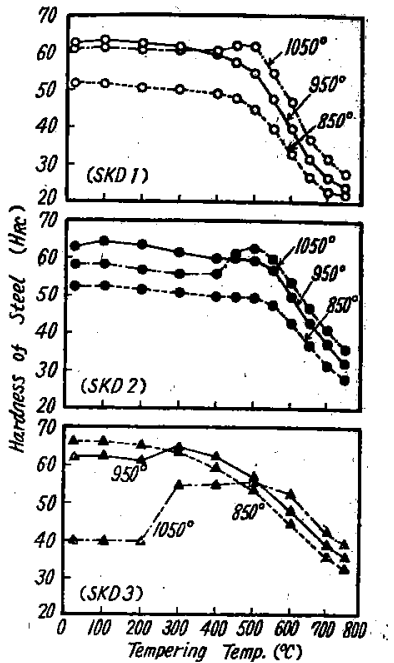

Fig. 7. Hardness of cold-working die steels, after quenching and tempering for $1 \mathrm{~h}$.

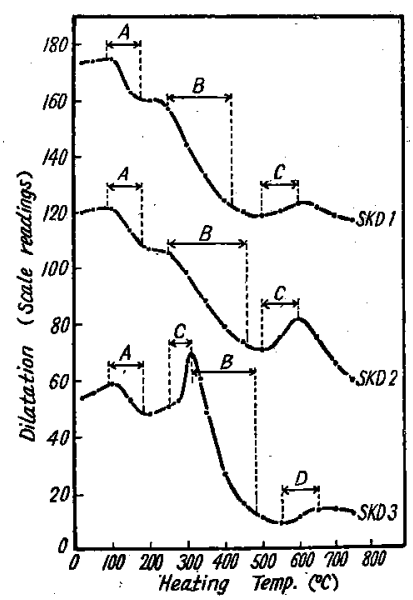

Fig. 8. Differential dilatation curves for die steels, quenched from $950^{\circ} \mathrm{C}$. (heating rate; about $1^{\circ} \mathrm{C} / \mathrm{mn}$ ).

B： $\theta$ 炭化物の形成红伴う収縮

$\mathrm{C}$ ：残留オーステナイトの分解に伴う膨脤

$D$ ：特殊炭化物 $\left(\mathrm{M}_{6} \mathrm{C}\right)$ の形成に伴5膨脹 $\left.{ }^{8}\right)$

(b) 焼戻に伴う炭化物の諸変化

前報までに報告したごとく，電解分離法によれば烧る によつて析出する炭化物の種類, 組成, 形状等が烧㞔》 度ならびに焼戻時間に依存していちじるしく変化するて とを詳細に実験するととができる。しかしなから，野 ダイス鋼は焼入組織中に多量の未溶解炭化物を含有し? 
Table 5. Chemical composition of matrix steels, prepared as similar to the matrix in quenched SKD 2 and SKD 3, respectively.

\begin{tabular}{c|c|c|c|c|c|c|c}
\hline Steel designation & C & Si & Mn & P & S & Cr & W \\
\hline S K D 2-M & $\cdot 60$ & $\cdot 19$ & $\cdot 59$ & .026 & .021 & $6 \cdot 46$ & $1 \cdot 97$ \\
S K D 3-M & $\cdot 51$ & $\cdot 25$ & $\cdot 40$ & .019 & .024 & $1 \cdot 15$ & $2 \cdot 67$ \\
\hline
\end{tabular}

いるので，これを焼㞔した後電解を行うと，烧屎によつ て析出した炭化物と，末溶解炭化物とが混合して分蜼さ れるから，焼扊によつて析出した炭化物のみについて， その本性を究明することができない。

したがつて，前報门におけると同棣に，烍入組織中の 基質と全く同一組成の装地鋼を熔製して，乙れ焼戻実 験の試料とした. Table 5 は SKD 2 ならひに SKD 3 の基地鋼として熔製した試料（SKD 2-M，ならびに SKD 3-M) の化学組成であつて, Table 4 に示したSKD 2ならびに SKD3 の㜔入組織中の基質の組成とほ心゙ 一致した組成を有している。これらの基地銅を $1050^{\circ} \mathrm{C}$ から焼入れて，組織中に未溶解炭化物が存在しないこと を確認した後，400〜 $800^{\circ} \mathrm{C}$ の各温度に 1 時間烓戾した ものについて実験を行つた・

Fig.9，10 は，基地鋼の焼戻組織中から分嚾した炭化 物の $\mathrm{Cr}, \mathrm{W}$ 浱度の分析結果, ならびに炭化物のX線迴 折像加ら判定した各炭化物の存在温度篹国を図示したも のである.いずれの基地鋼においても，400〜 $500^{\circ} \mathrm{C} の$ 㜔戻を行つた組織中儿存在寸る炭化物恃，セメンンイト に若干の $\mathrm{Cr}, \mathrm{W}$ の固溶した $\theta$ 炭化物であるが, $550^{\circ} \mathrm{C}$ 以上の烍戻において蛙，蛙戻温度の上昇ととるに，先ず Cr が炭化物に浱集し，ついでWむ炭化物に浱集する.

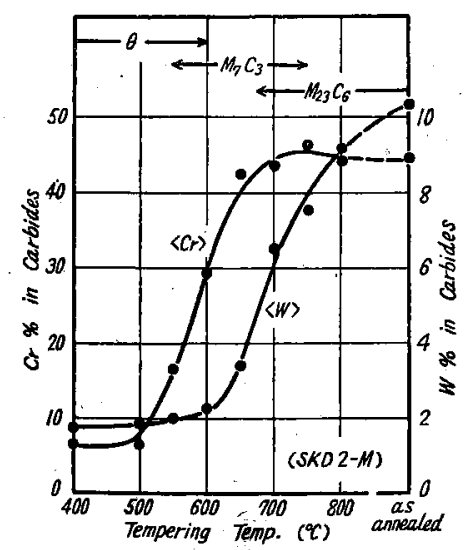

Fig. 9. Chemical and $\mathrm{X}$-ray analysis of carbides, isolated from the matrix steel (SKD 2-M), tempered at various temperatures for $1 \mathrm{~h}$.

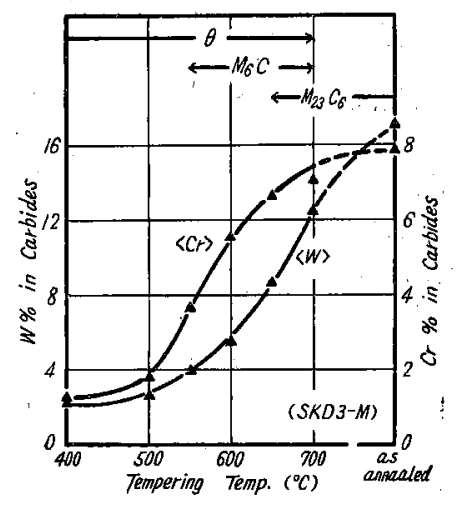

Fig. 10. Chemical and $\mathrm{X}$-ray analysis of carbides, isolated from the matrix steel (SKD 3-M), tempered at various temperatures for $1 \mathrm{~h}$.

これに伴つて炭化物の種類も变化しており， SKD2-M においては $\theta$ 炭化物についで $\mathrm{M}_{7} \mathrm{C}_{3}$ ならびに $\mathrm{M}_{23} \mathrm{C}_{6}$ が 順次現れ，また SKD3-M においては，日炭化物について $\mathrm{M}_{6} \mathrm{C}$ ならびに $\mathrm{M}_{23} \mathrm{C}_{6}$ が形成されることが認められた。

(c) 暁扊に伴う炭化物の挙動 (考察)

以上の実験からダイス鋼定政戻した場合の炭化物の挙 動について次のごとく考えられる. (i) $80 \sim 120^{\circ} \mathrm{C}$ の熄 戻によつて $\varepsilon$ 炭化物が形成される.ついで (ii) 250 人 $400^{\circ} \mathrm{C}$ の焼戻によつて $\theta$ 崖化物が形成される．この場合 の たらびに $\theta$ 炭化物は基地鋼とほぶ同量の $\mathrm{Cr}, \mathrm{W}$ あ るいは Moを固溶している. (iii) 焼戻温度が $500^{\circ} \mathrm{C}$ 以 上となると特殊元素の原子が移動しうるようになるので $\theta$ 炭化物に対して特殊元素が浱集すると同時に, 特殊炭 化物を形成し始める。㤐なわち, 高 $\mathrm{C}$-高 $\mathrm{Cr}-\mathrm{W}$ ダイス 鋼（SKD2）に和いては Cr を主体とした特殊炭化物 $\mathrm{M}_{7} \mathrm{C}_{3}$ がまず形成され，ついで $\mathrm{M}_{23} \mathrm{C}_{6}$ が現れる。W は $\theta$ または $\mathrm{M}_{7} \mathrm{C}_{3}$ にはあまり固溶しないが， $\mathrm{M}_{23} \mathrm{C}_{6}$ には 約 $20 \%$ まで固溶しうるがら， $\mathrm{M}_{23} \mathrm{C}_{6}$ が発生し始るる と急に炭化物に対する W の濃集度が上昇する. また高 C-高 W ダイス鋼（SKD3）においては Cr 含有量が 少いので，W を主体とした特殊炭化物 $\mathrm{M}_{6} \mathrm{C}$ がまず形

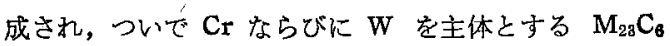
が現れる9. 
な拉，高 C-高 Cr-Mo ダイス銅 (SKD11) について

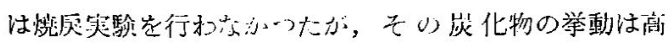

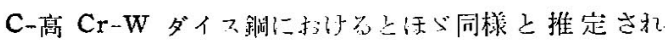
る.

\section{III. 結 言}

冷間ダイス鈰 (SKD 1， SKD 2, SKD 11 ならびに

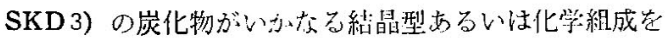

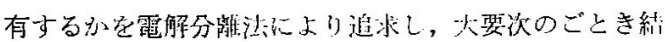
果老た。

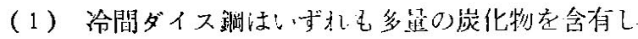
ており，とくに，SKD3 は㘹鈍状態に括いて約 $42 \% \sigma$ ，

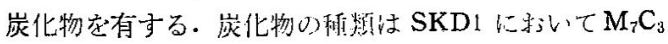
SKD2 に括它 $\mathrm{M}_{23} \mathrm{C}_{6}+\mathrm{M}_{7} \mathrm{C}_{3}$ ， SKD11 に执に $\mathrm{M}_{23} \mathrm{C}_{6}, \operatorname{SKD} 3$ に方・て $\mathrm{M}_{23} \mathrm{C}_{6}+\mathrm{M}_{6} \mathrm{C}$ でる。 (Table 2)

（2）焼入によりた $\mathrm{M}_{23} \mathrm{C}_{6}$ は $\mathrm{M}_{7} \mathrm{C}_{3}$ よりもオーステ

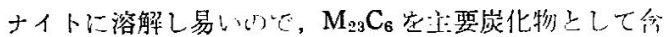
标しているSKD2, SKD11 ならざに SKD3 は, $\mathrm{M}_{7} \mathrm{C}_{3}$

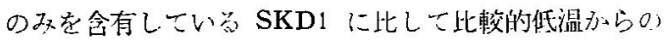

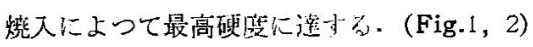

（3）常用の焼入温成方ら硬化した場公の基質の新成 は次のごをくであそ. (Fig. 4, 5, 6, Table 4)

$\operatorname{SKD} 1$ ( $950^{\circ} \mathrm{C}$ 㷔入 $): 0.6 \% \mathrm{C}, 4.4 \% \mathrm{Cr}$

SKD $2\left(980^{\circ} \mathrm{C}\right.$ 焼入) : $0.7 \% \mathrm{C}, 6.4 \% \mathrm{Cr}, 1.7 \% \mathrm{~W}$

SKD $11\left(1000^{\circ} \mathrm{C}\right.$ 慌入 $): 0.5 \% \mathrm{C}, 6.0 \% \mathrm{Cr}, 0.5 \% \mathrm{Mo}$
SKD $3\left(850^{\circ} \mathrm{C}\right.$ 览入): $0.5 \% \mathrm{C}, 1 \cdot 0 \% \mathrm{Cr}, 2.5 \% \mathrm{~W}$

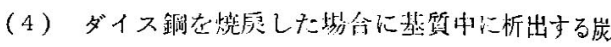

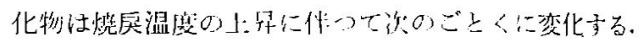

(Fig. 3, 9, 10)

$$
\begin{aligned}
& \text { SKD 1: } \varepsilon \rightarrow \theta \rightarrow \mathrm{M}_{7} \mathrm{C}_{3} \\
& \text { SKD 2: } \varepsilon \rightarrow \theta \rightarrow \mathrm{M}_{7} \mathrm{C}_{3} \rightarrow \mathrm{M}_{23} \mathrm{C}_{6} \\
& \text { SKD 1 1: } \varepsilon \rightarrow \theta \rightarrow \mathrm{M}_{7} \mathrm{C}_{3} \rightarrow \mathrm{M}_{23} \mathrm{C}_{6} \\
& \text { SKD } 3: \varepsilon \rightarrow \theta \rightarrow \mathrm{M}_{6} \mathrm{C} \rightarrow \mathrm{M}_{23} \mathrm{C}_{6}
\end{aligned}
$$

終りに䜿久種々御協力をいたづいた慗北大学工学部助 教授，金子秀夫博土ならびに三蔆造船压崎製浩所，本田 裕修士に厚く感謝する。

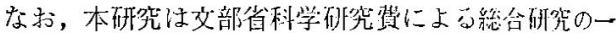

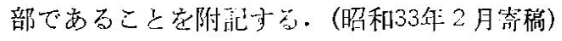

$$
\text { 交献 }
$$

1) 佐藤, 本田, 西沢: 鉄々䞒, 42 (1956), 1118

2) 仵:藤, 西沢, 大楿：日本金属学全誌，21(1957), 662

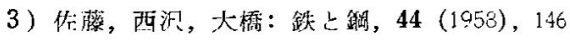

4) 仵:藤, 西沢: 鉄已钲, 43 (1957), 1069

5 ) 小柴, 永鼠：鉡上鋁，39 (1953)，119

6) W. Tofaute, C. Küttner, A. Büttinghaus, Arch. Eisenhüttenw. 9 (1935/36), 607

7) J. R. Lane, N. J. Grant, Trans. A. S. M., 44 (1952), 113

8) 佐藤, 西讯：日本金属学会，1953年4月諈演

a) K. Kuo, J.I.S.I, 186 (19.57), 297 